\title{
Modified Silica Adsorbents for Toluene Adsorptions under Dry and Humid Conditions: Impacts of Pore Size and Surface Chemistry
}

Shuai Liu ${ }^{\mathrm{a}}$, Yue Peng*a, Tao Yanª, Yani Zhang ${ }^{\mathrm{a}}$, John Crittenden ${ }^{\mathrm{b}}$ and Junhua Li ${ }^{\mathrm{a}}$

a State Key Joint Laboratory of Environment Simulation and Pollution Control, National Engineering Laboratory for Multi Flue Gas Pollution Control Technology and Equipment, School of Environment, Tsinghua University, Beijing 100084, China

${ }^{b}$ Brook Byers Institute for Sustainable Systems and School of Civil and Environmental Engineering, Georgia Institute of Technology, 828 West Peachtree Street, Atlanta, Georgia, 30332, United States

Tel.: +8610 62771093, Fax: +861062771093

E-mail: pengyue83@tsinghua.edu.cn

Supplementary Information for Langmuir. 


\section{Contents}

Section S1. The method of D-R model...........................................................................

Section S2. The calculation of Biot number and the HSDM fitting .......................................

Section S3. The BET surface area calculated from the water isotherms ..................................5

Figure S1. The TG/DSC curves of the mesoporous silica with template P123. .......................6

Figure $\mathrm{S} 2$. The $\mathrm{N}_{2}$ adsorption/desorption isotherms of pure silica and phenyl modified silica. 7

Figure S3. D-R isotherm plots obtained for the adsorption of toluene on the 2triphnl-cal

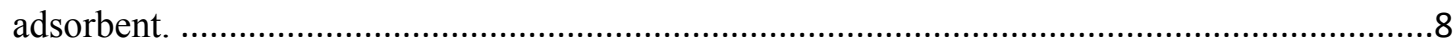

Figure S4. The static adsorption isotherms of toluene (a) and water (b) over the 2phnl-cal and

2triphnl-cal adsorbents.

.9

Figure S5. The toluene dynamic adsorption curves and the simulation curves of Y-N model on pure silica (a), phnl-wash, phnl-cal and triphnl-cal (b), 2phnl-cal and 2triphnl-cal (c) under no humidity conditions at $25^{\circ} \mathrm{C}$

Figure S6. The TG/DTG curves of pure silica and phenyl modified silica saturated with toluene.

Figure S7. The toluene dynamic adsorption curves of typical silica adsorbents under high humidity conditions of $90 \%$ relative humidity at $25{ }^{\circ} \mathrm{C}$......

Figure S8. The BET surface area calculated from water vapor adsorption isotherms at $25^{\circ} \mathrm{C}$.

Table S1. The mass loss and the density of silanol on pure silica.

Table S2. Textural properties of the pure and phenyl modified silica adsorbents. .15

Table S3. The mass loss and the density of silanol on pure silica. .16

References 
Section S1. The method of D-R model.

The isotherm can be fitted by D-R model as follow:

$$
\ln W=\ln W_{0}-B\left(\frac{R T}{\mu}\right)^{2}\left(\ln \frac{P_{0}}{P}\right)^{2}
$$

Where

$\mathrm{W}=$ amount of adsorbate adsorbed on adsorbent, mmol adsorbate/g adsorbent.

$\mathrm{W}_{0}=$ maximum amount of adsorbate adsorbed on adsorbent, mmol adsorbate $/ \mathrm{g}$ adsorbent.

$\mathrm{B}=$ microporosity constant determined by adsorbent, $\mathrm{cm}^{6} \mathrm{~J}^{-2}$.

$\mu=$ polarizability, $\mathrm{mL} \mathrm{mol}^{-1}$.

For the VOCs whose dipole moment is less than 2 debyes, polarizability can be estimated from the refractive index using Lorenz-Lorentz equation:

$$
\mu=\frac{\left(\eta^{2}-1\right) M_{W}}{\left(\eta^{2}+2\right) \rho_{l}}
$$

Where

$\eta=$ refractive index, unitless.

$\mathrm{M}_{\mathrm{w}}=$ molecular weight, $\mathrm{g} \mathrm{mol}^{-1}$.

$\rho_{l}=$ liquid density of $\mathrm{VOC}, \mathrm{g} \mathrm{mL}^{-1}$. 
Section S2. The calculation of Biot number and the HSDM fitting

The Biot number is calculated by the following equation ${ }^{1-2}$ :

$$
\mathrm{Bi}=\frac{K_{f} R(1-\varepsilon)}{D_{s} D_{g} \varepsilon}
$$

Where

$\mathrm{Bi}=$ solute gas-phase mass transfer rate/solute intraparticle mass transfer rate.

$\mathrm{K}_{\mathrm{f}}=$ fluid-phase mass transfer coefficient, $\mathrm{m} \mathrm{s}^{-1}$.

$\mathrm{R}=$ the radius of adsorbent particle, $\mathrm{m}$.

$\varepsilon=$ bed void fraction.

$\mathrm{K}_{\mathrm{f}}, \mathrm{D}_{\mathrm{g}}$ and $\mathrm{D}_{\mathrm{s}}$ are calculated using the previous equations. ${ }^{1}$

In addition, $1 / \mathrm{n}$ is the paremeter of the Freundlich equation as follow:

$$
Q=K P^{\frac{1}{n}}
$$

Where

$Q=$ amount of adsorbate adsorbed on adsorbent, mmol adsorbate/g adsorbent.

$\mathrm{K}, 1 / \mathrm{n}$ : related parameters.

With parameters $\mathrm{Bi}$ and $1 / \mathrm{n}$, the breakthrough curves can be plotted using following equation:

$$
T=\frac{V C_{0} t}{M q_{e}}=A_{0}+A_{1}\left(\frac{C_{t}}{C_{0}}\right)^{A_{2}}+\frac{A_{3}}{1.01-\left(\frac{C_{t} A_{4}}{C_{0}}\right)}
$$

Where

$\mathrm{T}=$ mass throughout, dimensionless.

$\mathrm{V}=$ gas flow rate, $\mathrm{m}^{3} \mathrm{~s}^{-1}$

$\mathrm{M}=$ mass of adsorbent, $\mathrm{g}$

$\mathrm{q}_{\mathrm{e}}=$ solid-phase concentration in equilibrium with $\mathrm{C}_{0}, \mathrm{mg} \mathrm{g}^{-1}$.

$\mathrm{A}_{0}, \mathrm{~A}_{1}, \mathrm{~A}_{2}, \mathrm{~A}_{3}, \mathrm{~A}_{4}$ are related parameters, which can be ensured by $\mathrm{Bi}$ and $1 / \mathrm{n} \cdot{ }^{1-3}$ 
Section S3. The BET surface area calculated from the water isotherms

The linear BET equation is as follow:

$$
\frac{P}{n\left(P_{0}-P\right)}=\frac{1}{n_{m} C}+\frac{C-1 P}{n_{m} C P_{0}}
$$

Where

$\mathrm{P}=$ partial pressure, $\mathrm{Pa}$.

$\mathrm{P}_{0}=$ saturated vapor pressure, $\mathrm{Pa}$

$\mathrm{n}=$ the adsorption amount at $\mathrm{P}, \mathrm{mmol} \mathrm{g}^{-1}$

$\mathrm{n}_{\mathrm{m}}=$ the adsorption amount of monolayer adsorption, mmol g-1

$\mathrm{C}=$ the constant, dimensionless

The surface area is calculated with the equation:

$$
S_{\text {water }}=n_{m} S N_{A}
$$

Where

$\mathrm{S}_{\mathrm{water}}=$ BET surface area calculated from water vapor isotherms, $\mathrm{m}^{2} \mathrm{~g}^{-1}$ $\mathrm{S}=$ the cross section area of $\mathrm{H}_{2} \mathrm{O}$ molecule at $25^{\circ} \mathrm{C}, \mathrm{m}^{2}$ 


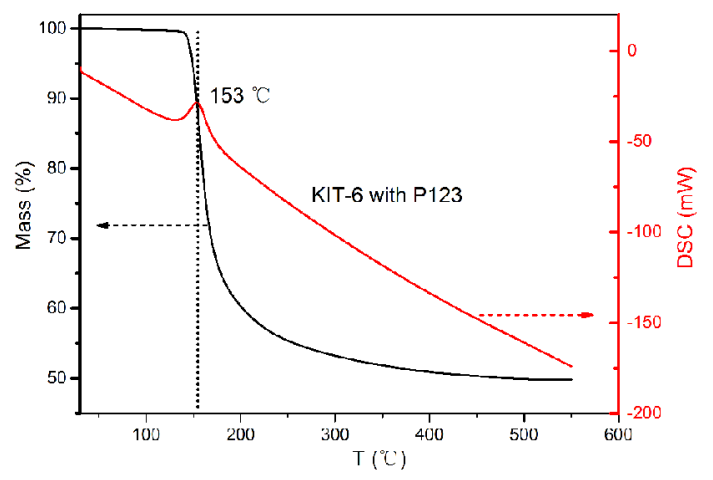

Figure S1. The TG/DSC curves of the mesoporous silica with template P123. 


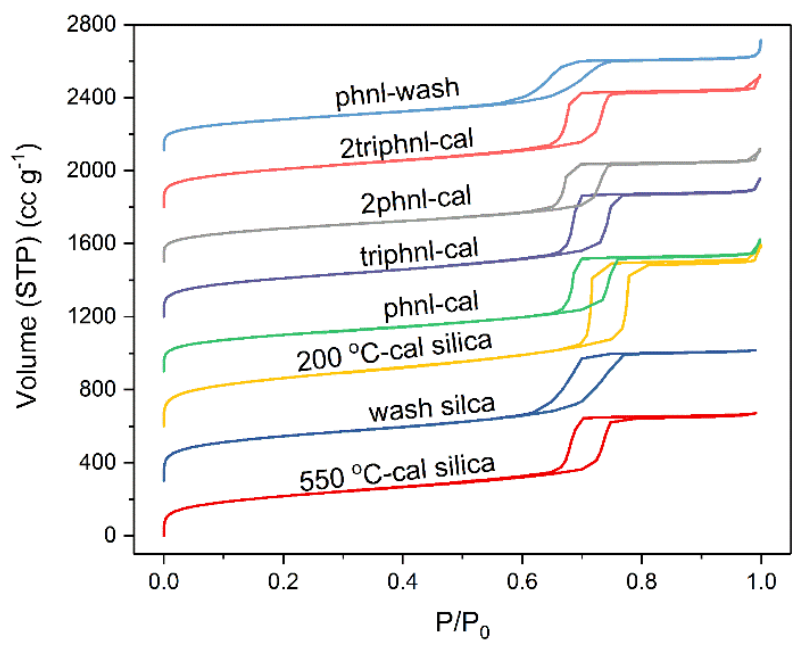

Figure S2. The $\mathrm{N}_{2}$ adsorption/desorption isotherms of pure silica and phenyl modified silica. 


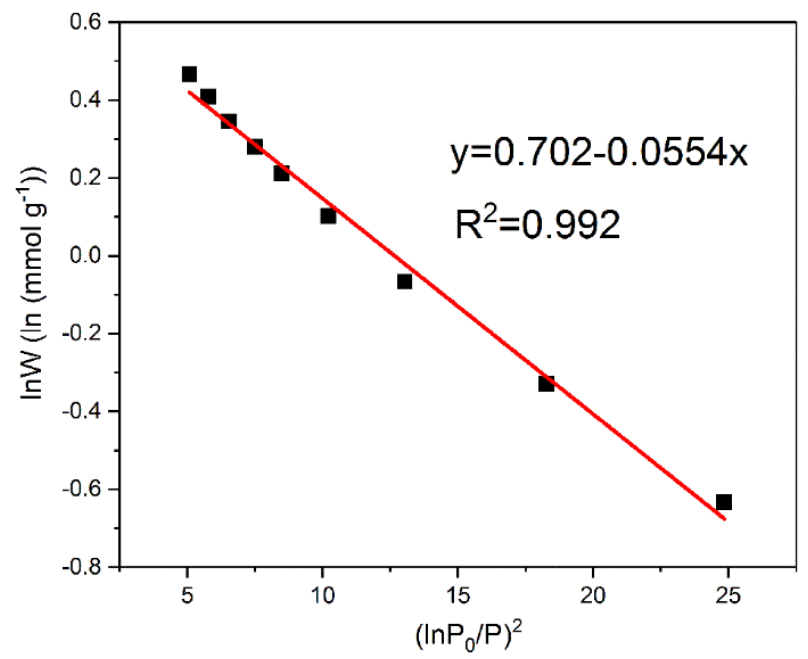

Figure S3. D-R isotherm plots obtained for the adsorption of toluene on the 2triphnlcal adsorbent. 

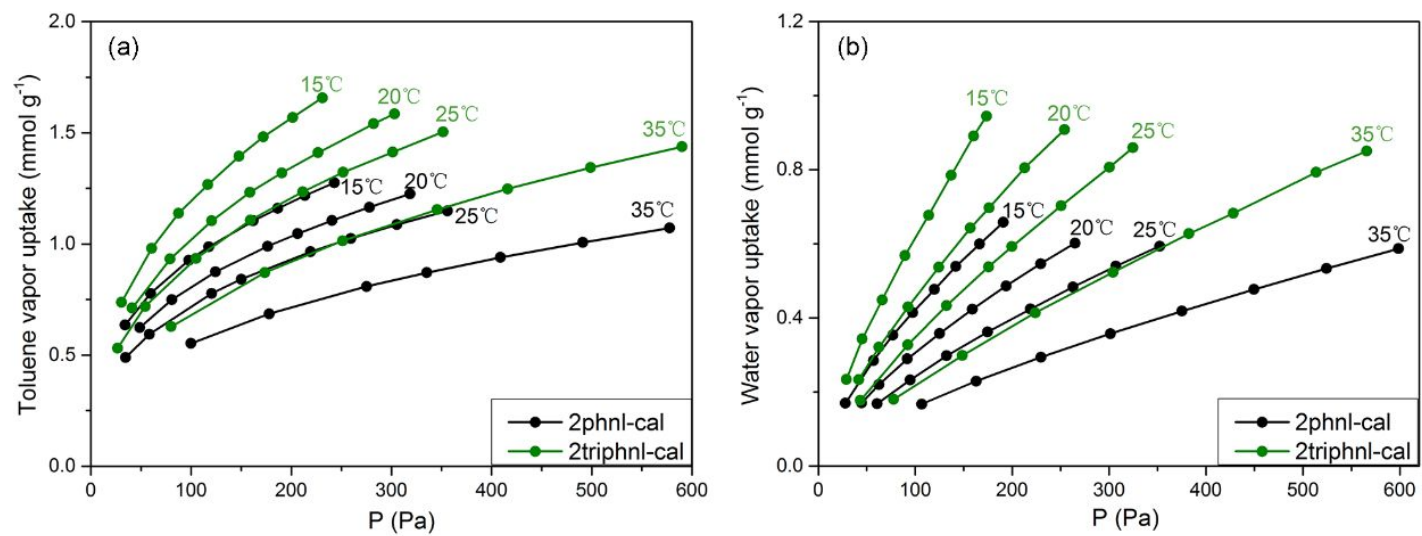

Figure S4. The static adsorption isotherms of toluene (a) and water (b) over the 2 phnlcal and 2triphnl-cal adsorbents. 

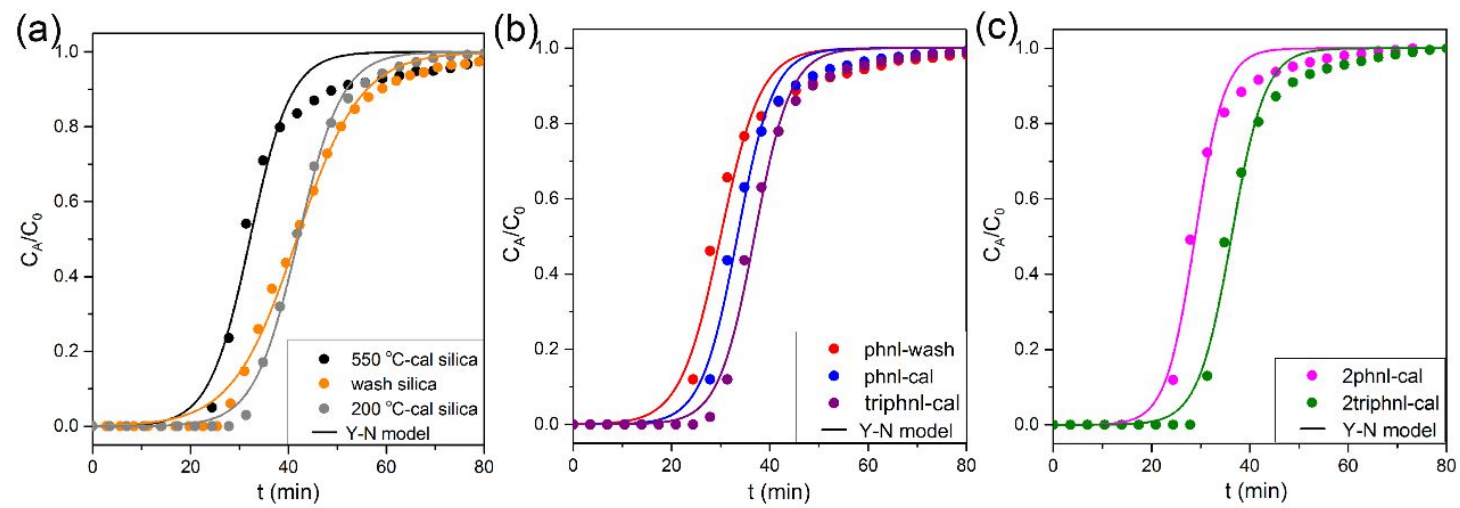

Figure S5. The toluene dynamic adsorption curves and the simulation curves of Y-N model on pure silica (a), phnl-wash, phnl-cal and triphnl-cal (b), 2phnl-cal and 2triphnl-cal (c) under no humidity conditions at $25{ }^{\circ} \mathrm{C}$ 


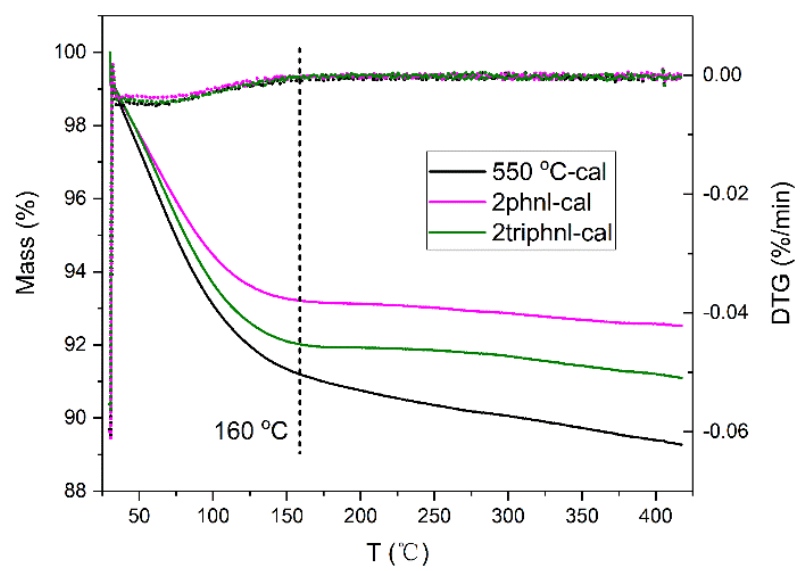

Figure S6. The TG/DTG curves of pure silica and phenyl modified silica saturated with toluene. 


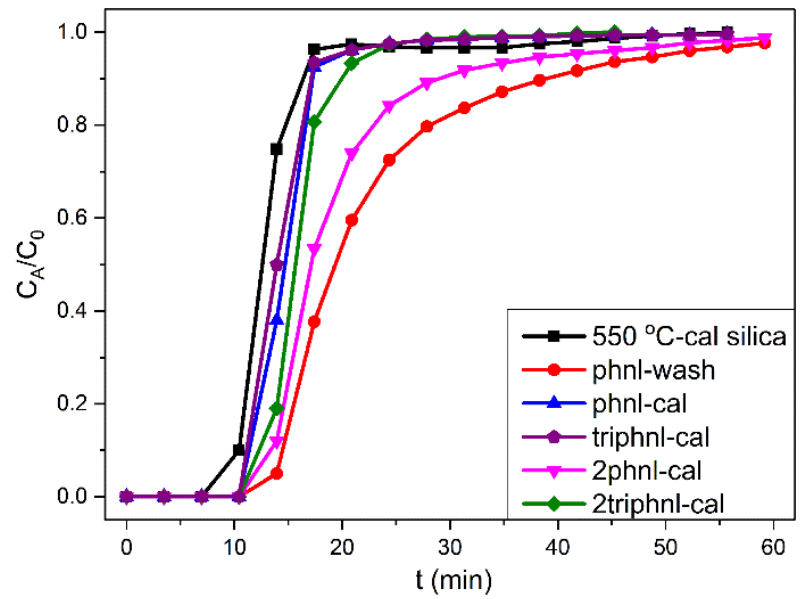

Figure S7. The toluene dynamic adsorption curves of typical silica adsorbents under high humidity conditions of $90 \%$ relative humidity at $25^{\circ} \mathrm{C}$. 


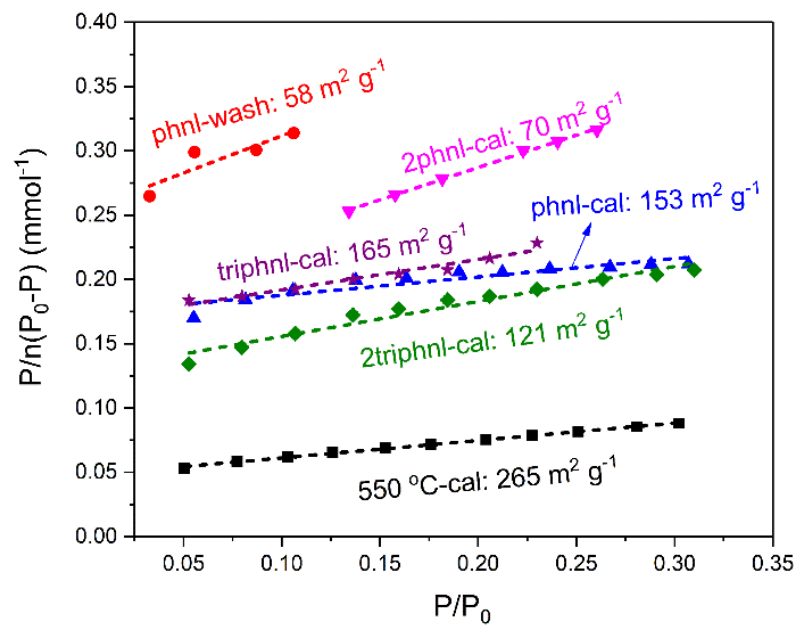

Figure S8. The BET surface area calculated from water vapor adsorption isotherms at $25{ }^{\circ} \mathrm{C}$. 
Table S1. The mass loss and the density of silanol on pure silica.

\begin{tabular}{cccc}
\hline Samples & $550^{\circ} \mathrm{C}$-cal silica & wash silica & $200{ }^{\circ} \mathrm{C}$-cal silica \\
\hline $\begin{array}{c}\text { Mass loss at } 200-1100 \\
{ }^{\circ} \mathrm{C}(\text { wt. } \%)\end{array}$ & 3.4 & 9.9 & 9.5 \\
$\begin{array}{c}\text { Density of silanol }(\mathrm{OH} \\
\left.\mathrm{nm}^{-2}\right)\end{array}$ & 2.9 & 7.5 & 6.7 \\
\hline
\end{tabular}


Table S2. Textural properties of the pure and phenyl modified silica adsorbents.

\begin{tabular}{ccccccccc}
\hline \multirow{2}{*}{ Samples } & $\begin{array}{c}550^{\circ} \mathrm{C}- \\
\text { cal silica }\end{array}$ & $\begin{array}{c}\text { wash } \\
\text { silica }\end{array}$ & $\begin{array}{c}200{ }^{\circ} \mathrm{C}- \\
\text { cal silica }\end{array}$ & $\begin{array}{c}\text { phnl- } \\
\text { wash }\end{array}$ & $\begin{array}{c}\text { phnl- } \\
\text { cal }\end{array}$ & $\begin{array}{c}\text { triphnl- } \\
\text { cal }\end{array}$ & $\begin{array}{c}\text { 2phnl- } \\
\text { cal }\end{array}$ & $\begin{array}{c}\text { 2triphnl- } \\
\text { cal }\end{array}$ \\
\hline$S_{\mathrm{A}}\left(\mathrm{m}^{2} \mathrm{~g}^{-1}\right)$ & 780 & 886 & 955 & 650 & 724 & 761 & 662 & 754 \\
$S_{\mathrm{MA}}\left(\mathrm{m}^{2} \mathrm{~g}^{-1}\right)$ & 288 & 336 & 343 & 200 & 260 & 242 & 259 & 256 \\
$V_{\mathrm{P}}\left(\mathrm{cm}^{3} \mathrm{~g}^{-1}\right)$ & 1.04 & 1.11 & 1.54 & 0.95 & 1.12 & 1.17 & 0.96 & 1.10 \\
$V_{\mathrm{MP}}\left(\mathrm{cm}^{3} \mathrm{~g}^{-1}\right)$ & 0.13 & 0.15 & 0.15 & 0.09 & 0.12 & 0.10 & 0.12 & 0.11 \\
$D_{\mathrm{P}}(\mathrm{nm})$ & 8.2 & 8.2 & 9.1 & 7.3 & 8.5 & 8.5 & 8.2 & 8.2 \\
\hline
\end{tabular}


Table S3. The mass loss and the density of silanol on pure silica.

\begin{tabular}{cccccc}
\hline Samples & $\mathrm{K}_{\mathrm{f}}\left(\mathrm{m} \mathrm{s}^{-1}\right)$ & $\mathrm{D}_{\mathrm{g}}$ & $\mathrm{Ds}\left(\mathrm{m}^{2} \mathrm{~s}^{-1}\right)$ & $\mathrm{Bi}$ & $1 / \mathrm{n}$ \\
\hline $550{ }^{\circ} \mathrm{C}$-cal silica & \multirow{2}{*}{$5.64 \times 10^{-3}$} & $3.37 \times 10^{7}$ & $4.08 \times 10^{-15}$ & 18.7 & 0.5 \\
2triphnl-cal & & $3.66 \times 10^{7}$ & $3.75 \times 10^{-15}$ & 18.2 & 0.4 \\
\hline
\end{tabular}


References

1. John C. Crittenden, R. R. T., Kerry J. Howe, Water Treatment-Principles and Design(3rd Ed). John Wiley \& Sons: New Jersey.

2. Hand, D. W.; Crittenden, J. C.; Thacker, W. E., Simplified Models for Design of Fixed-Bed Adsorption Systems. J Environ Eng-Asce 1984, 110 (2), 440-456.

3. Crittenden, J. C.; Cortright, R. D.; Rick, B.; Tang, S. R.; Perram, D., Using Gac to Remove Vocs from Air Stripper Off-Gas. J Am Water Works Ass 1988, 80 (5), 73-84. 